\title{
Experimental Behavior of Bolted T-Stub Connections with IPE Standard Profile
}

\author{
Mahyar Maali' ${ }^{1}$, Mahmut Kılıç ${ }^{1}$, Merve Sağıroğlu² and Abdulkadir Cüneyt Aydın ${ }^{1^{*}}$ \\ ${ }^{1}$ Department of Civil Engineering, Faculty of Engineering, Ataturk University, Erzurum, Turkey \\ ${ }^{2}$ Department of Civil Engineering, Faculty of Engineering and Architecture, Erzurum Technical University, Erzurum, Turkey
}

\begin{abstract}
In this research, new connection types were suggested, and their behaviors were determined using full-scale experiments. T-shaped combinations created using the IPE standard profile and T-shaped elements are different from those in the literature, which utilize welded plates. Thus, problems occurring at the welds of connections such as the occurrence of fracture points and inability to perform well in place are expected to be eliminated. To recommend the use of weld-less T connections, knowledge of the behavior of the connections was needed. In addition, in this research, the effects of changes in the dimensions of the connection members on the connection behavior were examined for the T-connection type. This provided information about the optimum sizes of the connection elements. The main parameters observed were the evolution of the resistance, stiffness, rotation capacity, ductility of a joint, and energy dissipation. The aim was to provide the necessary data to improve Eurocode 3 and efficiently use residue IPE standard profiles, rather than send them back to the consumption cycle.
\end{abstract}

Keywords: Full-scale experiment; IPE standard profile; T connection; Eurocode 3; Stiffness

Nomenclature: $\mathrm{F}_{\mathrm{u}}$ Ultimate or tensile stress; $\mathrm{F}_{\mathrm{y}}$ Yield stress; $\mathrm{E}_{\mathrm{st}}$ Strain hardening modulus; $\rho_{\mathrm{y}}=\mathrm{f}_{\mathrm{y}} / \mathrm{f}_{\mathrm{u}}$ : Yield ratio; $\varepsilon_{\mathrm{st}}$ Strain at strain hardening point; $\varepsilon_{\text {uni: }}$ Uniform strain; $\varepsilon_{\mathrm{f}}$ Strain at rupture load; X: Cartesian axis; distance; E: Young's modulus; I: Moment of inertia; M: Bending moment; $\mathrm{M}_{\mathrm{i} \text {.Rd: }}$ Joint flexural plastic (design) resistance; $\mathrm{M}_{\mathrm{j} \text { max: }}$ Maximum bending moment; $\mathrm{M}_{\min . \mathrm{K}-\mathrm{R}:}$ Lower resistance bound of the knee-range of the joint moment-rotation curve; $M_{\text {sup.K-R: }}$ Upper resistance bound of the kneerange of the joint moment-rotation curve; $M_{\theta . \mathrm{Cd}}$ Bending moment at fracture of the joint; $\mathrm{P}$ : Concentrated force; $\mathrm{S}_{\mathrm{j} \text {.ini }}$ : Initial rotational stiffness of a joint; $S_{\text {j.p-1: }}$ Post-yield rotational stiffness of a joint; $\theta_{\text {Cd: }}$ Rotation capacity of a connection; $\theta_{\text {Mimax: }}$ Rotation of the connection at maximum load; $\theta_{\text {M.j.R: }}$ Connection rotation analytical value at which the moment resistance first reaches $\left(\mathrm{M}_{\mathrm{j} . \mathrm{Rd}}\right) ; \theta_{\min \mathrm{K}-\mathrm{R} \text { : }}$ Rotation between the lower bound of the knee-range of the joint moment-rotation curve and the rotation capacity; $\theta_{\text {sup K-R: }}$ Rotation between the upper bound of the knee-range of the joint moment-rotation curve and the rotation capacity; $\Psi \mathrm{j}_{\text {max }_{\max }}$ : load Joint ductility index evaluated for the rotation at maximum load; $\Psi \mathrm{j}$ : Joint ductility index; $\theta$ : Rotation; $\mathrm{DT}_{\mathrm{i}:} L_{\mathrm{LDT}} \mathrm{DT}_{\mathrm{i}} ; \mathrm{ST}_{\mathrm{i}:}$ Strain gauge

\section{Introduction}

It is necessary to take into account the behavior of connections in the design and analysis of steel frames because it represents the actual behavior [1]. Thus, the behavior of the connections should be well known. Because the most important force transmitted by the connections in a frame is the moment, the connection behavior is represented by the rotational deformation. The connections produce various moment-rotation curves according to the type of connection, elements of connection, and shape of placement. Experimental studies are used to determine these curves. Tests on some connections were performed, and a database was created. To express the connection behavior in an analysis, classifications were performed and mathematical models were created using this database. Yet, these have been limited to the seven connection types defined in the literature [2-21]. However, there are many different types of beam-column connections in steel structures today that are not defined in data banks. Coelho et al. [22] assessed the behavior of 32 bolted T-stub connections made of welded plates. Swanson et al. [23] conducted several tests on individual T-stubs to show that their behavior was partly influenced by the bending of the bolts. Abidelah et al. [24] researched the experimental and analytical behavior of bolted end-plate connections with or without stiffeners. The experimental results of eight specimens of steel bolted beam-to-column and beam-to-beam connections with flush or extended end plates were investigated. Four of the connections had the end plates reinforced with stiffeners in the extended parts. Herrera et al. [25] investigated the behavior of built-up T-stubs subjected to tensile loading using numerical and experimental models. T-shaped combinations created using the IPE standard profile and T-shaped elements are different from those in the literature, which utilize welded plates. Thus, the elimination of the problems occurring at the welds of connections such as the occurrence of fracture points and the inability to perform well in place is expected. To recommend the use of weld-less $\mathrm{T}$ connections, knowledge of their behavior is needed. However, T-stub connections that use the IPE standard profile are not mentioned and investigated in either Eurocode 3 or the literature, as in this research.

Thus, the aim of this study was to analyze the influence of $\mathrm{T}$ connections that utilize the IPE standard profile on the behavior of steel connections, to provide the necessary data for improving Eurocode 3 and efficiently use residue IPE standard profiles, rather than send them back to the consumption cycle. Moment-rotation curves were used to evaluate the main parameters characterizing the behavior of the tested connections, such as the resistance moment, stiffness, rotation capacity, and energy dissipation.

\section{Experimental Program}

\section{Test details and mechanical properties}

This paper presents the nine experimental models that were developed to predict the behavior of bolted T-stub connections under static loads in three groups: T300, T270, and T240 (T300 cut from of IPE300 standard Profile, T270 cut from of IPE270 standard Profile, and

${ }^{*}$ Corresponding author: Abdulkadir Cüneyt Aydın, Faculty of Engineering, Department of Civil Engineering, Ataturk University-25240, Erzurum, Turkey, Tel: +90 44223147 81; E-mail: acaydin@atauni.edu.tr

Received October 24, 2017; Accepted May 24, 2018; Published May 29, 2018

Citation: Maali M, Kılıç M, Sağıroğlu M, Aydın AC (2018) Experimental Behavior of Bolted T-Stub Connections with IPE Standard Profile. J Civil Environ Eng 8: 312 doi: 10.4172/2165-784X.1000312

Copyright: (c) 2018 Maali M, et al. This is an open-access article distributed under the terms of the Creative Commons Attribution License, which permits unrestricted use, distribution, and reproduction in any medium, provided the original author and source are credited. 
T240 cut from of IPE240 standard Profile). The experimental program is shown in Figure 1, and the details are listed in Table 1. The behaviors of the T-stub joints were compared within their groups $\left(\mathrm{T} 300-\mathrm{H}_{\max }, \mathrm{T} 300-\right.$ $\mathrm{H}_{\text {min }}, \mathrm{T} 300-\mathrm{H}_{\mathrm{av}}, \mathrm{T} 270-\mathrm{H}_{\max }, \mathrm{T} 270-\mathrm{H}_{\min }, \mathrm{T} 270-\mathrm{H}_{\mathrm{av}}, \mathrm{T} 240-\mathrm{H}_{\max }, \mathrm{T} 240-\mathrm{H}_{\min }$, and $\left.\mathrm{T} 240-\mathrm{H}_{\mathrm{av}}\right)(\mathrm{H}=$ height of beam to height of T-stub joint). Column stiffeners with a thickness equal to $10 \mathrm{~mm}$ were welded to the column by means of a continuous $45^{\circ}$ fillet weld. Thus, columns with a large cross section were chosen, and the use of the stiffener prevented excessive deflection in the flange column. The fillet welding was performed from the upper side of the joint in the down-hand position in the workshop. A consumable electrode was used in the manual metal arc welding process [26]. The plate stiffener, T-stub profile, and profile section was S235. HE160B was used for the columns, and IPE240 was selected for the beams. Hand-tightened full-threaded grade $8.8 \mathrm{M} 14$ bolts in 16-mm drilled holes were used consistently for all the tested specimens. The aim of the study was to analyze the influence of $\mathrm{T}$ connections that used the IPE standard profile on the behavior of steel connections, to provide the necessary data for improving Eurocode 3.

Coupon tension tests of the structural steel materials of the column stiffener, T-stub profile, flange, and web of the beam and column were performed in accord with UNE-EN 10002-1 [27]. The average characteristic values for the structural steels and bolts (8.8) are listed in Table 2. This table gives the values for the Young's modulus (E), strain hardening modulus $\left(\mathrm{E}_{\mathrm{st}}\right)$, static yield and tensile stresses $\left(\mathrm{f}_{\mathrm{y}}\right.$ and $\mathrm{f}_{\mathrm{u}}$, respectively), yield ratio $\left(\rho_{\mathrm{y}}=\mathrm{f}_{\mathrm{y}} / \mathrm{f}_{\mathrm{u}}\right)$, strain at the strain hardening point $\left(\varepsilon_{\text {st }}\right)$, uniform strain $\left(\varepsilon_{\text {uni }}\right)$, and strain at the rupture load $\left(\varepsilon_{\mathrm{f}}\right)$. Each bolt (8.8) was tested under tension in order to determine the mechanical properties of the bolt material, in accordance with ISO 898-1999(E) [28].

\section{Test arrangement and instrumentation}

The specimens were subjected to a static force applied by a $900-\mathrm{kN}$ hydraulic jack with a maximum piston stroke of $300 \mathrm{~mm}$. Tests were performed under displacement control with a constant speed of 0.01 $\mathrm{mm} / \mathrm{s}$ up to the collapse of the specimens. In order to prevent the lateral torsional buckling of the beam during loading, a two-column guidance device near the beam was provided [29]. In fact, the experiments found that the lateral torsional buckling of the beam did not occur during loading. An illustration of the test arrangement and mechanism is shown in Figure 2. This study aimed to develop a realistic stress pattern at the connection, and the fracture of several specimens, i.e., the ultimate load, was attained with the specific testing machine [29]. Thus, $1500 \mathrm{~mm}$ was chosen as the length of the beam and column.

The main requirements for the instrumentation were measurements of (1) the applied load (P), which was measured using a load cell and hydraulic pump; (2) the displacements (DT) of the connection, beam, T-stub joint, and flange of the column, which were measured using linear variable displacement transducers (linear variable displacement transducers with a maximum displacement of $100 \mathrm{~mm}$ (LVDTs, shown as DT in Figure 2)); and (3) the strains at the T-stub connections, which were measured using strain gauges (TML YEFLA-5 (a maximum strain of $15 \%$ to $20 \%)$ ). The results were collected using a data logging device that recorded all of the measurements and load cell values at 1-s intervals. All of the data were recorded for the duration of the test. Four strain gauges (ST) were added to the T-stub connection (horizontal and vertical), as shown in Figure 1, to observe the strain distribution. For a good comparison of the results, all of the specimens used the same arrangement for the locations of the strain gauges and measuring devices.

The designed connections produced various moment-rotation curves that described the relationship between the applied moment $(\mathrm{M})$ and the corresponding rotation $(\theta)$ for the members according to the elements of the connection and shape of the placement [1]. The rotation and bending moment $(\mathrm{M})$ were predicted using the displacements of the beam and top-and-seat angle connection multiplied by the distance between the load application point and beam end bolted to the column $\left(\mathrm{L}_{\text {load }}\right)$, respectively:

$$
\mathrm{M}=\mathrm{PL}_{\text {load }}
$$

\begin{tabular}{|c|c|c|c|c|c|c|}
\hline Groups Name & Experiment & T-stub Joint & $H_{\max }=h y_{\max } / \mathbf{h}$ & $H_{\min }=h y m i n / h$ & $\mathrm{H}_{\mathrm{av}}=\mathrm{Hyav} / \mathrm{h}$ & $X(\mathrm{~mm})$ \\
\hline \multirow{3}{*}{ T300 group } & $\mathrm{T} 300-\mathrm{H}_{\max }$ & \multirow{3}{*}{ IPE 300} & 1 & - & - & \\
\hline & $\mathrm{T} 300-\mathrm{H}_{\min }$ & & - & 0.63 & - & \\
\hline & $\mathrm{T} 300-\mathrm{H}_{\mathrm{av}}$ & & - & - & 0.82 & \\
\hline \multirow{3}{*}{ T270 group } & $\mathrm{T} 270-\mathrm{H}_{\max }$ & \multirow{3}{*}{ IPE 270} & 1 & - & - & \\
\hline & $\mathrm{T} 270-\mathrm{H}_{\min }$ & & - & 0.63 & - & \\
\hline & $\mathrm{T} 270-\mathrm{H}_{\mathrm{av}}$ & & - & - & 0.82 & \\
\hline \multirow{3}{*}{ T240 group } & $\mathrm{T} 240-\mathrm{H}_{\max }$ & \multirow{3}{*}{ IPE 240} & 1 & - & - & 215 \\
\hline & $\mathrm{T} 240-\mathrm{H}_{\min }$ & & - & 0.63 & - & \\
\hline & $\mathrm{T} 240-\mathrm{H}_{\mathrm{av}}$ & & - & - & 0.82 & \\
\hline
\end{tabular}

$h_{y}=$ Height of beam, $h=$ Height of T-stub joint, av=Average, max=Maximum, min=Minimum, $X=$ Lengths of T-stub joints

Table 1: Test details.

\begin{tabular}{|c|c|c|c|c|c|c|c|c|}
\hline Variables & $\mathrm{E}(\mathrm{MPa})$ & $\mathrm{E}_{\mathrm{st}}(\mathrm{MPa})$ & $\mathrm{f}_{\mathrm{y}}(\mathrm{MPa})$ & $\mathrm{f}_{u}(\mathrm{MPa})$ & $\rho_{y}$ & $\varepsilon_{\mathrm{st}}$ & $\varepsilon_{\text {uni }}$ & $\varepsilon_{\mathrm{f}}$ \\
\hline $10 \mathrm{~mm}$ plate & 205352 & 1798 & 687 & 721 & 1 & $2.71 \times 10^{-2}$ & $2.68 \times 10^{-2}$ & $1.62 \times 10^{-1}$ \\
\hline Bolt & ----- & ----- & 1127 & 1247 & 0.9 & ----- & ---- & ----- \\
\hline Beam Web & 203521 & 1374 & 521 & 649 & 0.8 & $1.81 \times 10^{-2}$ & $1.59 \times 10^{-2}$ & $1.09 \times 10^{-1}$ \\
\hline Beam Flange & 204399 & 1399 & 562 & 685 & 0.8 & $1.97 \times 10^{-2}$ & $1.68 \times 10^{-2}$ & $1.15 \times 10^{-1}$ \\
\hline Column Web & 204424 & 1396 & 541 & 637 & 0.9 & $1.89 \times 10^{-2}$ & $1.63 \times 10^{-2}$ & $1.11 \times 10^{-1}$ \\
\hline Column Flange & 208242 & 1928 & 831 & 945 & 0.9 & $2.99 \times 10^{-2}$ & $2.81 \times 10^{-2}$ & $1.78 \times 10^{-1}$ \\
\hline T300-stub web & 204121 & 1425 & 581 & 705 & 0.8 & $2.18 \times 10^{-2}$ & $1.80 \times 10^{-2}$ & $1.38 \times 10^{-1}$ \\
\hline T300-stub Flange & 204781 & 1499 & 638 & 735 & 0.9 & $2.43 \times 10^{-2}$ & $1.99 \times 10^{-2}$ & $1.69 \times 10^{-1}$ \\
\hline T270-stub web & 204001 & 1394 & 545 & 671 & 0.8 & $1.90 \times 10^{-2}$ & $1.66 \times 10^{-2}$ & $1.13 \times 10^{-1}$ \\
\hline T270-stub Flange & 204498 & 1428 & 588 & 702 & 0.8 & $2.00 \times 10^{-2}$ & $1.70 \times 10^{-2}$ & $1.21 \times 10^{-1}$ \\
\hline
\end{tabular}

Table 2: Average characteristic values for structural steels and bolts. 
Citation: Maali M, Kılıç M, Sağıroğlu M, Aydın AC (2018) Experimental Behavior of Bolted T-Stub Connections with IPE Standard Profile. J Civil Environ Eng 8: 312 doi: 10.4172/2165-784X.1000312

Page 3 of 8

The rotational deformation of the joint $(\theta)$ is equal to the connection rotation. The beam rotation is approximately given by (Figure 2):

$$
\theta=\frac{\arctan \left(\delta_{D T 1}-\delta_{D T S}-\left(-\frac{P}{E I}\right)\left(\frac{X_{D T 1}^{3}}{6}-\frac{L_{\text {load }} X_{D T 1}^{2}}{2}\right)\right)}{L 1}
$$

where I is the moment of inertia, and E is Young's modulus of the beam. Some of the differences among the results for the LVDTs (DT1DT2) were identical, as expected. Therefore, all of the deformation values presented throughout the remainder of the section refer to the readings from DT1 [29].

\section{Moment-rotation curve}

The M- $\theta$ curve of the connection may be characterized using the aforementioned relationships. The main features of this curve are the plastic flexural resistance, $M_{j . R d}$, which corresponds to the intersection point of the previous two regression lines obtained for the initial stiffness $\left(\mathrm{S}_{\mathrm{j} . \mathrm{ini}}\right)$ and post-limit stiffness $\left(\mathrm{S}_{\mathrm{j} . \mathrm{p}-1}\right)$ and its corresponding rotation $\Theta_{\mathrm{M}^{*} \mathrm{Rd}}$; the maximum bending moment, $\mathrm{M}_{\mathrm{i} \text { max }}$ and its corresponding rotation, $\Theta_{M^{*} ; \text { max }} ;$ the knee-range of the $M-\theta$ curve, which is defined as the transition zone between the initial and post-limit stiffness values, with its lower boundary at $M_{\text {mink-R }}$ and rotation $\Theta_{\text {mink-R }}$, and with its upper

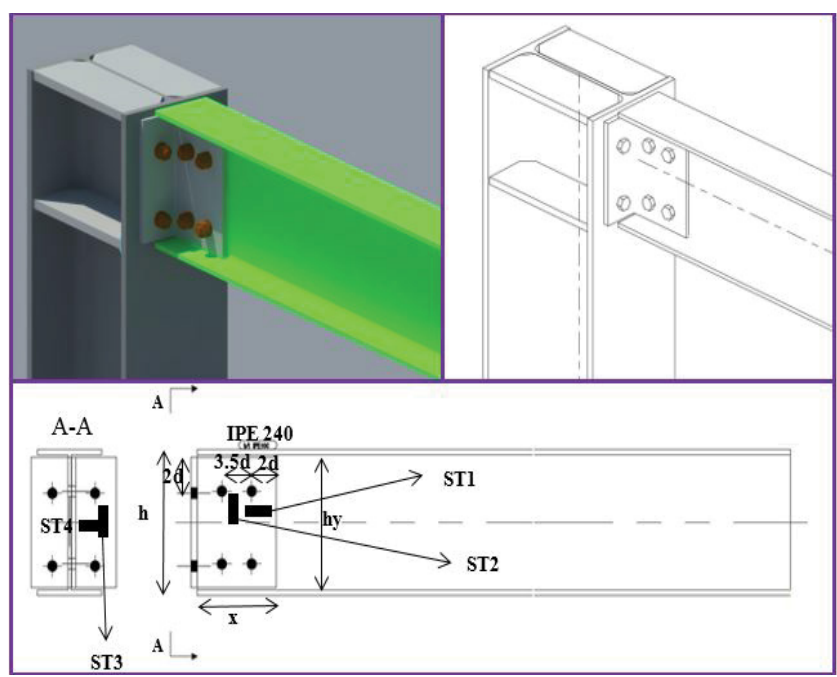

Figure 1: T-stub geometry, proposed three-dimensional semi-rigid joint, and locations of strain gauges (ST1=parallel to beam on T-stub, ST2=perpendicular to beam on T-stub, ST3=parallel to column on T-stub, ST4=perpendicular to column on T-stub, and d=diagonal to bolts). limit at $\mathrm{M}_{\text {supk-R }}$ and rotation $\Theta_{\text {supk-R }}$; and the bending moment capacity, $M_{\theta_{C d}}$, and its corresponding rotation capacity, $\theta_{c d}$. In particular, the following characteristics were assessed in the different experimental tests [29-31], as shown in Figure 3.

The ductility of a joint $(\Psi \mathrm{j})$ is a property that reflects the length of the yield plateau of the moment-rotation response. The proposed definition of the ductility of a joint is the difference between the rotation value corresponding to the joint plastic resistance, $\theta_{\mathrm{MRd}}$, and the total rotation capacity, $\theta_{\mathrm{Cd}}$ [32-33] (Figure 3). Thus, the ductility of a joint relates the maximum rotation of the joint, $\theta_{\mathrm{Cd}}$, to the rotation value corresponding to the joint's plastic flexural resistance, $\theta_{\mathrm{MRd}}$ [29]:

$$
\Psi_{j}=\frac{\theta C d}{\theta M R d}
$$

In addition, the rotation values at the maximum load and corresponding ductility levels, $\Psi$ j.max load, can be derived as follows:

$$
\Psi_{j \cdot \max \text { load }}=\frac{\theta M j \cdot \max }{\theta M R d}
$$

The conclusions concerning the ductility of a joint and the rotation values at the maximum load and corresponding ductility levels will be explained in section 3. Eurocode 3 [34] gives quantitative rules for predicting the joint flexural plastic resistance and initial rotational

\begin{tabular}{|c|c|c|c|c|c|c|c|c|c|c|c|c|c|c|c|c|}
\hline \multirow{2}{*}{ Group } & \multirow{2}{*}{ Experiment } & \multicolumn{4}{|c|}{ Resistance (KN.m) } & \multicolumn{3}{|c|}{ Stiffness (KN m/rad) } & \multicolumn{5}{|c|}{ Rotation (rad) } & \multirow{2}{*}{$\Psi_{\mathrm{j}}$} & \multirow{2}{*}{$\underset{\text { load }}{\Psi_{j . m a x}}$} & \multirow{2}{*}{$\begin{array}{c}\text { Energy } \\
\text { Dissipated } \\
\text { (kN.m.rad) }\end{array}$} \\
\hline & & KR (knee-range) & $\mathbf{M}_{\mathrm{j}, \mathrm{Rd}}$ & $\mathbf{M}_{\mathrm{j} \text { max }}$ & $M_{e c d}$ & $\mathbf{S}_{\mathrm{j} . \mathrm{nin}}$ & $\mathbf{S}_{\mathrm{j}, \mathrm{p}-1}$ & $S_{j . j i n i} / S_{j . p-p-1}$ & $\boldsymbol{\theta}_{\text {M.Rd }}$ & $\boldsymbol{\theta}_{\text {Min.K.R }}$ & $\boldsymbol{\theta}_{\text {Msup...R }}$ & $\boldsymbol{\theta}_{\mathrm{Mj} \cdot \max }$ & $\boldsymbol{\theta}_{\mathrm{cd}}$ & & & \\
\hline \multirow{3}{*}{ T300 } & $\mathrm{T} 300-\mathrm{H}_{\max }$ & $2.20-24.43$ & 23.48 & 27.54 & 25.67 & 1.15 & 0.28 & 4 & 0.068 & 0.0067 & 0.077 & 0.113 & 0.122 & 1.8 & 1.66 & 1.68 \\
\hline & $\mathrm{T} 300-\mathrm{H}_{\min }$ & $1.20-14.96$ & 9.38 & 18.51 & 17.1 & 1.61 & 0.6 & 2.68 & 0.048 & 0.0073 & 0.11 & 0.145 & 0.147 & 3.06 & 3.02 & 1.36 \\
\hline & $\mathrm{T} 300-\mathrm{H}_{\mathrm{av}}$ & $2.22-13.34$ & 10.16 & 18.96 & 17.66 & 1.6 & 0.39 & 4.09 & 0.046 & 0.0085 & 0.105 & 0.178 & 0.179 & 3.89 & 3.87 & 1.7 \\
\hline \multirow{3}{*}{ T270 } & $\mathrm{T} 270-\mathrm{H}_{\max }$ & $4.47-16.13$ & 11.94 & 19.16 & 19.16 & 3.45 & 0.26 & 13.13 & 0.015 & 0.0049 & 0.071 & 0.109 & 0.111 & 7.4 & 7.27 & 1.06 \\
\hline & $\mathrm{T} 270-\mathrm{H}_{\min }$ & $2.18-9.08$ & 4.5 & 14.22 & 14.01 & 3.79 & 0.79 & 4.79 & 0.012 & 0.004 & 0.076 & 0.146 & 0.151 & 12.6 & 12.17 & 1.07 \\
\hline & $\mathrm{T} 270-\mathrm{H}_{\mathrm{av}}$ & $4.75-16.58$ & 8.23 & 19.63 & 19.48 & 1.71 & 0.49 & 3.85 & 0.019 & 0.011 & 0.08 & 0.108 & 0.109 & 5.74 & 5.68 & 1.07 \\
\hline \multirow{3}{*}{ T240 } & $\mathrm{T} 240-\mathrm{H}_{\max }$ & $1.76-15.02$ & 7.83 & 21.75 & 21.01 & 2.32 & 0.55 & 4.17 & 0.018 & 0.0017 & 0.086 & 0.139 & 0.142 & 7.89 & 7.72 & 1.54 \\
\hline & $\mathrm{T} 240-\mathrm{H}_{\min }$ & $2.32-11.58$ & 5.68 & 12.22 & 11.22 & 3.53 & 0.39 & 9.05 & 0.015 & 0.0046 & 0.118 & 0.125 & 0.132 & 8.8 & 8.33 & 0.81 \\
\hline & $\mathrm{T} 240-\mathrm{H}_{\mathrm{av}}$ & $1.53-19.29$ & 12.63 & 21.53 & 20.8 & 1.95 & 0.33 & 5.85 & 0.051 & 0.0025 & 0.175 & 0.2185 & 0.219 & 4.29 & 4.28 & 2.35 \\
\hline
\end{tabular}

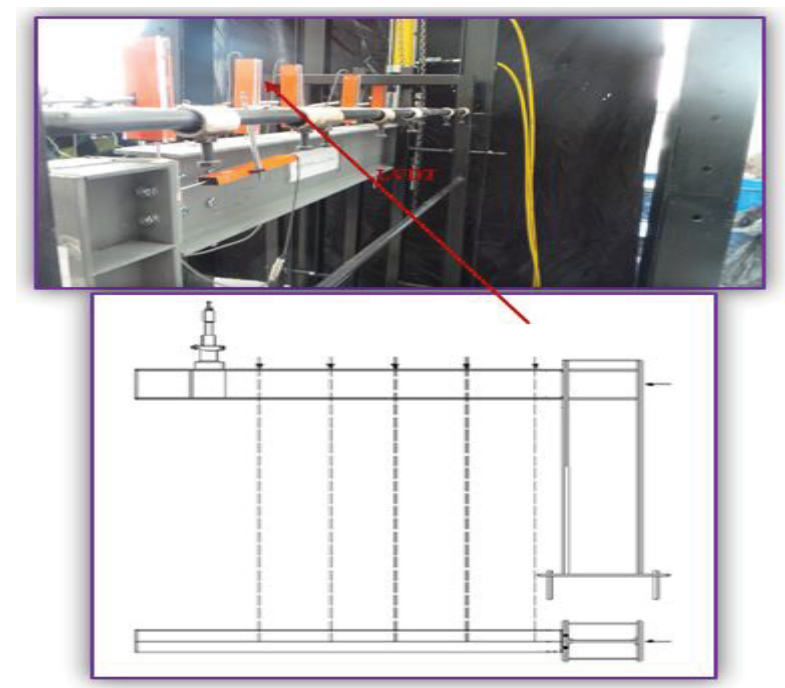

Figure 2: Locations of displacement transducers (DT=LVDTs)

Table 3: Moment-rotation characteristics. 
stiffness for the major beam-to-column joints of end-plate connections. These structural properties are evaluated below using the geometric and mechanical nominal properties in Eurocode 3.

\section{Results and Discussion}

The moment-rotation responses for the nine full-scale specimens of steel-bolted, beam-to-column connections with T-stub joints in three groups, T300- $\mathrm{H}_{\max }, \mathrm{T} 300-\mathrm{H}_{\min }, \mathrm{T} 300-\mathrm{H}_{\mathrm{av}}, \mathrm{T} 270-\mathrm{H}_{\max }, \mathrm{T} 270-\mathrm{H}_{\min }$, $\mathrm{T} 270-\mathrm{H}_{\mathrm{av}}, \mathrm{T} 240-\mathrm{H}_{\max }, \mathrm{T} 240-\mathrm{H}_{\min }$, and $\mathrm{T} 240-\mathrm{H}_{\mathrm{av}}(\mathrm{H}=$ height of beam to height of T-stub joint) are reported in Figure 4 and listed in Table 3. These curves and table show the following:

- The knee-range for the T300, T270, and T240 groups increased by about $61.55 \%, 40.82 \%$, and $30.16 \%$, respectively, with an increase in $\mathrm{H}$ from $\mathrm{H}_{\min }$ to $\mathrm{H}_{\max }$.

- The knee-range for the $\mathrm{H}_{\max }$ and $\mathrm{H}_{\min }$ models increased by about $40.35 \%$ to $47.55 \%$ and $32.70 \%$ to $49.85 \%$, respectively, with an increase in the thickness of the web and flange in the T240 to T300 T-stub joints. Meanwhile, the knee-range for the $\mathrm{H}_{\mathrm{av}}$ model decreased by about $33.20 \%$ to $37.21 \%$ with an increase in the thickness of the web and flange in T240 to T300 T-stub joints.

- The maximum knee-range was obtained with an increase in the thickness of the web and flange in T-stub joints and decrease in the height of the beam to height of the T-stub joint. For example, the knee-range was about $13.76 \mathrm{KN}$.m for $\mathrm{T} 300-\mathrm{H}_{\text {min }}$, whereas it was about $13.26 \mathrm{KN} . \mathrm{m}$ for $\mathrm{T} 240-\mathrm{H}_{\max }$. Thus, the thickness of the web and flange in the T-stub joints was important for the height of the beam to height of T-stub joint in the knee-range.

- The plastic flexural resistance values for the T300, T270, and T240 groups increased by about $56.72 \%$ to $60.51 \%, 31.07 \%$ to $62.31 \%$, and $27.46 \%$, respectively, with an increase in $\mathrm{H}$ from $\mathrm{H}_{\text {min }}$ to $\mathrm{H}_{\text {max }}$.

- The plastic flexural resistance values for the $\mathrm{H}_{\max }, \mathrm{H}_{\text {min }}$, and $\mathrm{H}_{\text {av }}$ model groups increased by about $49.14 \%$ to $66.65 \%, 12.26 \%$ to $39.44 \%$, and $18.99 \%$, respectively, with the increase in the thickness of the web and flange in the T240 to T300 T-stub joints. Thus, the maximum plastic flexural resistance was obtained with an increase in the thickness of the web and flange in the T-stub joints instead of an increase in the height of the beam to height of the T-stub joint.

- The maximum bending moments for the T300, T270, and T240 groups increased by about $31.15 \%$ to $32.75 \%, 25.78 \%$, and $1.05 \%$ to $43.84 \%$, respectively, with an increase in $\mathrm{H}$ from $\mathrm{Hmin}$ to $\mathrm{H}_{\max }$

- The maximum bending moments for the $\mathrm{H}_{\min }$ and $\mathrm{H}_{\mathrm{av}}$ model groups decreased by about $23.17 \%$ to $33.98 \%$ and $8.8 \%$ to $11.93 \%$, respectively, with an increase in the thickness of the web and flange in the T240 to T300 T-stub joints. Meanwhile, the maximum bending moment for the $\mathrm{H}_{\max }$ model increased by about $20.98 \%$ to $30.43 \%$ with an increase in the thickness of the web and flange in the T240 to T300T-stub joints.

- The bending moment capacities for the T300, T270, and T240 groups increased by about $31.20 \%$ to $33.38 \%, 26.88 \%$, and $0.99 \%$ to $46.56 \%$, respectively, with an increase in $\mathrm{H}_{\text {from } \mathrm{H}_{\min }}$ to $\mathrm{H}_{\max }$.

- The bending moment capacities for the $\mathrm{H}_{\max }$ and $\mathrm{H}_{\min }$ model groups increased by about $18.15 \%$ to $25.36 \%$ and $18.07 \%$ to $34.38 \%$, respectively, with an increase in the thickness of the web and flange in the T240 to T300 T-stub joints. Meanwhile, the maximum bending moment for the $\mathrm{H}_{\mathrm{av}}$ model decreased by about $6.34 \%$ to $15.09 \%$ with an increase in the thickness of the web and flange in the T240 to T300 T-stub joints.

- The rate of the increase in the initial stiffness to the post-limit stiffness for the T300 and T270 groups increased by about 33\% and $63.52 \%$ to $70.67 \%$, respectively, with an increase $\mathrm{H}$ from $\mathrm{H}_{\text {min }}$ to $\mathrm{H}_{\max }$. Meanwhile, the rate of the increase in the initial stiffness to the post-limit stiffness for the T240 model decreased by about $35.35 \%$ to $53.92 \%$ with an increase in $\mathrm{H}_{\text {from } \mathrm{H}_{\text {min }}}$ to $\mathrm{H}_{\max }$.

- The rates of the increase in the initial stiffness to the post-limit stiffness for the $\mathrm{H}_{\text {min }}$ and $\mathrm{H}_{\text {av }}$ model groups decreased by about $57.45 \%$ to $70.38 \%$ and $30.08 \%$ to $34.18 \%$, respectively, with an increase the thickness of the web and flange in the T240 to T300T-stub joints. Meanwhile, the rate of the increase in the initial stiffness to the post-limit stiffness for the $\mathrm{H}_{\max }$ model increased by about $68.24 \%$ with an increase in the thickness of the web and flange in the T240 to T300 T-stub joints. Generally, the rate of the increase in the initial stiffness to the post-limit stiffness decreased with an increase in the thickness of the web and flange in the T240 to T300 T-stub joints.

- The rotations of the plastic flexural resistance for the T300, T270, and T240 groups increased by about $29.41 \%$ to $32.35 \%, 20 \%$ to $36.84 \%$, and $16.66 \%$ to $70.58 \%$, respectively, with an increase in $\mathrm{H}$ from $\mathrm{H}_{\text {min }}$ to $\mathrm{H}_{\text {max }}$.

- The rotations of the plastic flexural resistance for the $\mathrm{H}_{\max }, \mathrm{H}_{\min }$ and $\mathrm{H}_{\mathrm{av}}$ models increased by about $73.53 \%$ to $77.94 \%, 68.75 \%$ to $75 \%$, and $58.69 \%$, respectively, with an increase in the thickness of the web and flange in the T240 to T300 T-stub joints.

- The maximum rotations for the T300, T270, and T240 groups decreased by about $18.53 \%$ to $36.52 \%, 25.34 \%$ to $26.02 \%$, and $36.38 \%$ to $42.79 \%$, respectively, with an increase in $\mathrm{H}_{\text {from }} \mathrm{H}_{\min }$ to $\mathrm{H}_{\max }$.

- The maximum rotations for the $\mathrm{H}_{\max }$ and $\mathrm{H}_{\mathrm{av}}$ model groups decreased by about $18.71 \%$ to $21.58 \%$ and $18.53 \%$ to $50.57 \%$, respectively, with an increase in the thickness of the web and flange in the T240 to T300 T-stub joints. Meanwhile, the maximum rotation for the $\mathrm{H}_{\min }$ model increased by about $13.79 \%$ to $13.89 \%$ with an increase in the thickness of the web and flange in the T240 to T300 T-stub joints. Generally, the maximum rotation increased with an increase in $\mathrm{H}_{\text {from } \mathrm{H}_{\text {min }}}$ to $\mathrm{H}_{\text {max }}$.

- The rotation capacities for the T300 and T240 groups increased by about $17.87 \%$ and $7.04 \%$ to $39.61 \%$, respectively, with an increase in $\mathrm{H}$ from $\mathrm{H}_{\text {min }}$ to $\mathrm{H}_{\max }$. Meanwhile, the rotation capacity

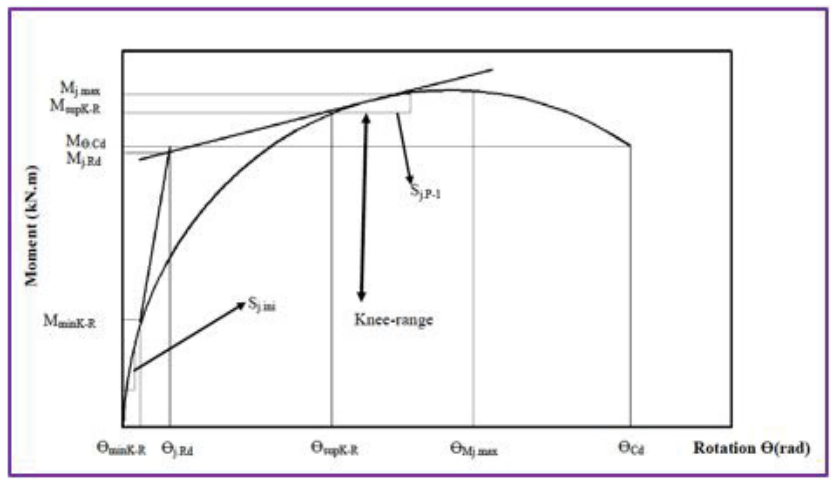

Figure 3: Moment-rotation curve characteristics. 


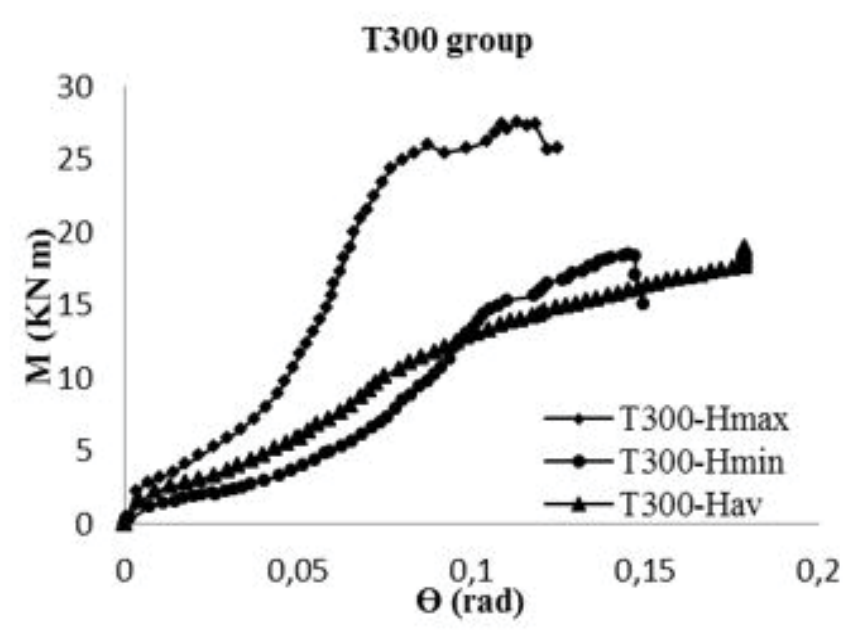

T270 group

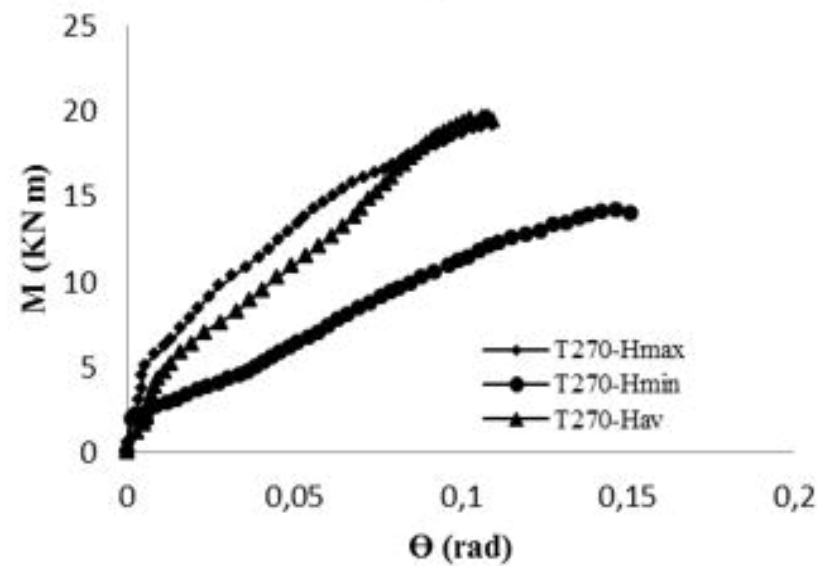

T240 group

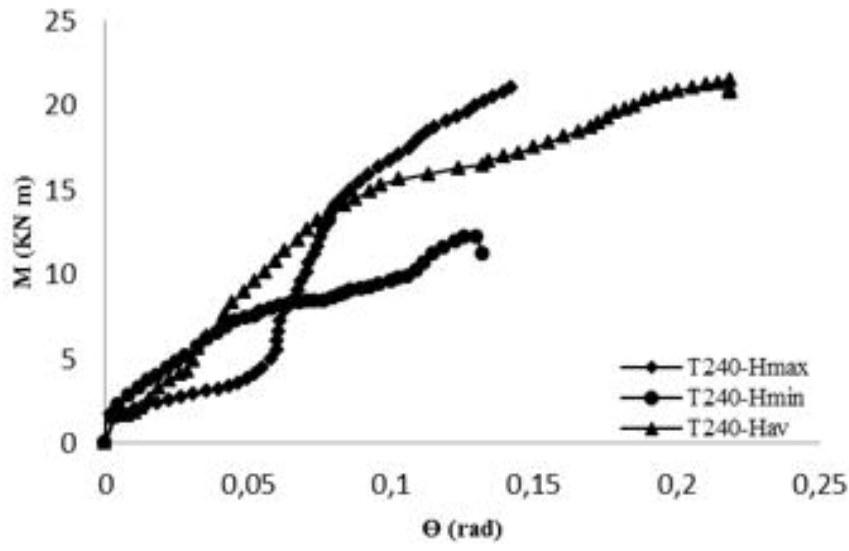

Figure 4: Moment-rotation curves for three groups.

for the T270 model decreased by about $26.46 \%$ with an increase in $\mathrm{H}$ from $\mathrm{H}_{\min }$ to $\mathrm{H}_{\max }$.

- The rotation capacities for the $\mathrm{H}_{\max }$ and $\mathrm{H}_{\mathrm{av}}$ model groups decreased by about $14.08 \%$ to $21.83 \%$ and $18.11 \%$ to $50.13 \%$, respectively, with an increase in the thickness of the web and flange in the T240 to T300 T-stub joints. Meanwhile, the maximum rotation for the $\mathrm{H}_{\min }$ model increased by about $10.20 \%$ to $12.58 \%$ with an increase in the thickness of the web and flange in the T240 to T300 T-stub joints.

- The $\Psi \mathrm{j}$ values for the T300, T270, and T240 groups decreased by about $41.50 \%, 41.17 \%$ to $54.45 \%$, and $11.36 \%$ to $51.36 \%$, respectively, with an increase in $\mathrm{H}$ from $\mathrm{H}_{\min }$ to $\mathrm{H}_{\max }$.

- The $\Psi \mathrm{j}$ values for the $\mathrm{H}_{\max }, \mathrm{H}_{\text {min }}$, and $\mathrm{H}_{\text {av }}$ models decreased by about $5.13 \%$ to $77.05 \%, 65.22 \%$, and $9.11 \%$, respectively, with an increase in the thickness of the web and flange in the T240 to T300 T-stub joints.

- The $\Psi \mathrm{j}_{\text {max.load }}$ values for the T300, T270, and T240 groups decreased by about $45.03 \%, 40.78 \%$ to $53.32 \%$, and $7.3 \%$ to $55.06 \%$, respectively, with an increase in $\mathrm{H}_{\text {from }} \mathrm{H}_{\min }$ to $\mathrm{H}_{\max }$.

- The $\Psi \mathrm{j}_{\text {max.load }}$ values for the $\mathrm{H}_{\text {max }}, \mathrm{H}_{\text {min }}$, and $\mathrm{H}_{\text {av }}$ models decreased by about $5.95 \%$ to $78.49 \%, 63.61 \%$, and $9.81 \%$, respectively, with an increase in the thickness of the web and flange in the T240 to T300 T-stub joints.

- The energy dissipations for the T300 and T240 groups increased by about $18.56 \%$ to $20 \%$ and $48.05 \%$ to $65.96 \%$, respectively, with an increase in $\mathrm{H}$ from $\mathrm{H}_{\min }$ to $\mathrm{H}_{\max }$.

- The energy dissipations for the $\mathrm{H}_{\max }, \mathrm{H}_{\min }$, and $\mathrm{H}_{\mathrm{av}}$ models increased by about $8.33 \%$ to $36.53 \%, 21.32 \%$ to $41.17 \%$, and $37.27 \%$, respectively, with an increase in the thickness of the web and flange in the T240 to T300 T-stub joints.

The moment-strain responses for the nine full-scale specimens of steel-bolted connections with T-stub joints in the three groups are reported in Figure 5. These curves show that there is also a correlation between the moment-rotation and moment-strain plots of these two completely different tools, which can be taken as further proof of the installation and measurement precision. As can be observed in Figure 5, at the point of failure for each specimen, all of the strains changed from elastic to plastic for the three groups of specimens.

Three collapse modes were observed during the tests: (i) the bolt being directly overloaded by the applied forces on the beam of the T-stub connection, (ii) shear of bolts on the column of T-stub connection, and (iii) 

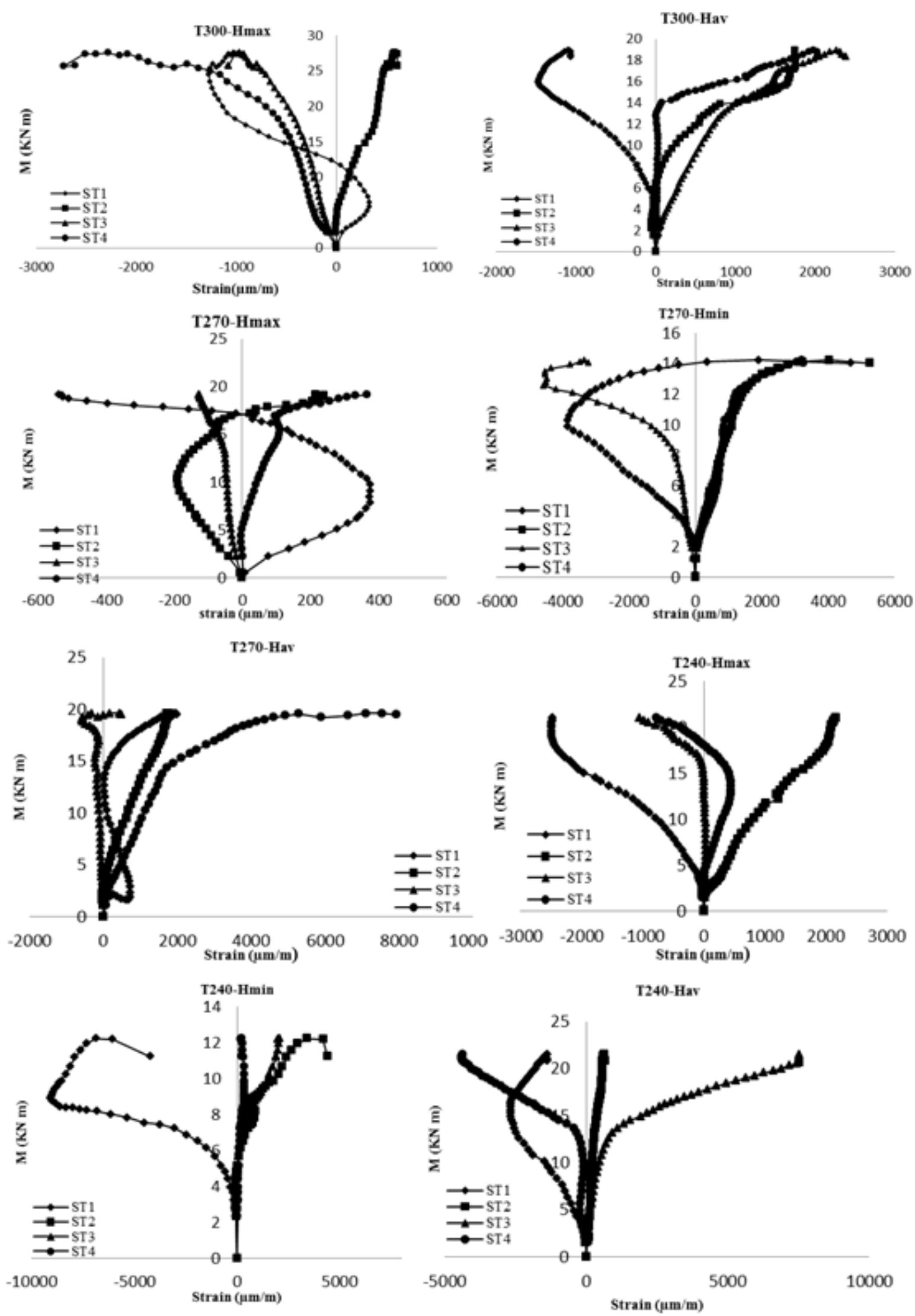

Figure 5: Moment-strain curves. 

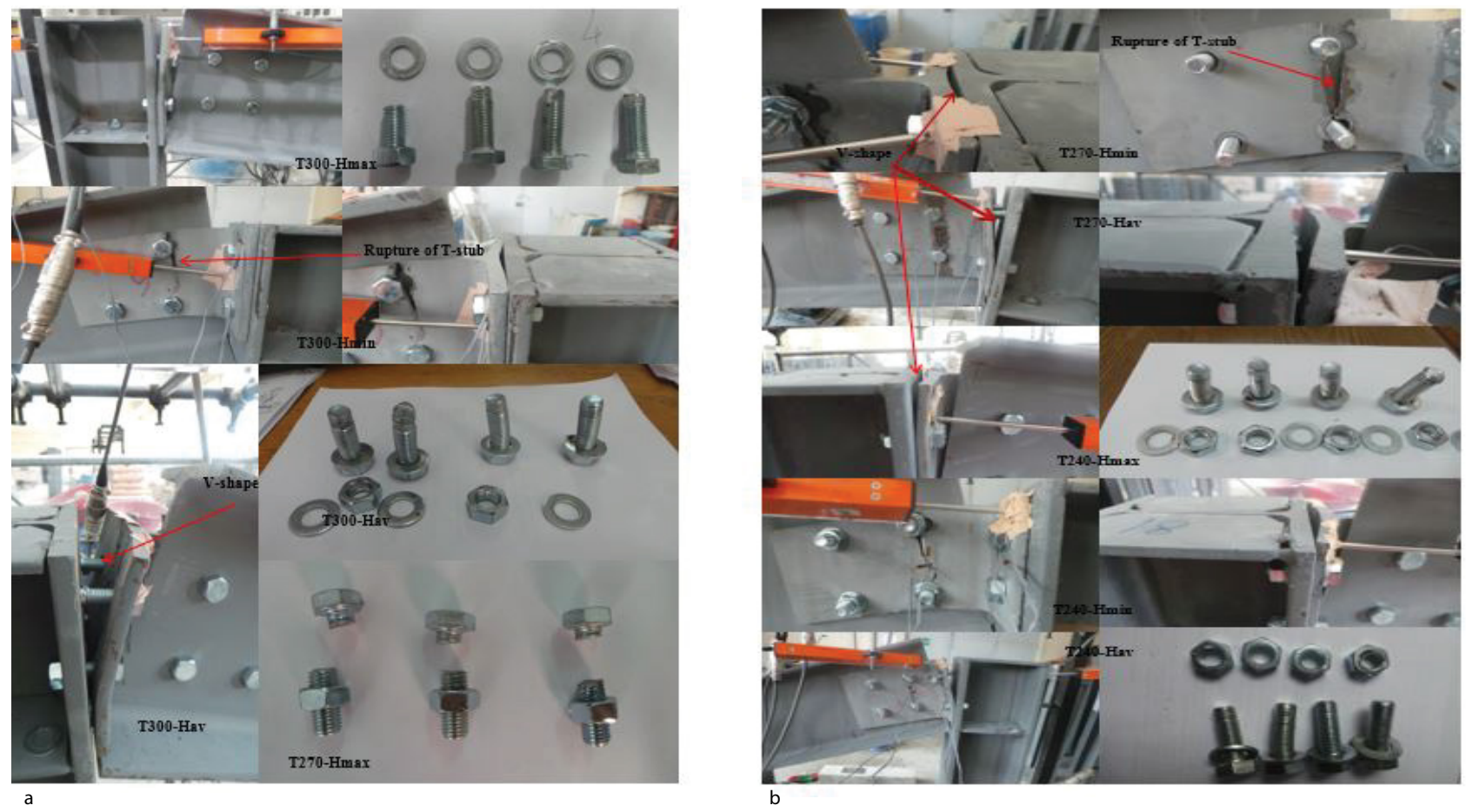

Figure 6: (a and b): Collapse of models.

rupture of T-stub connection on the beam (Figure 6a). The failure modes of the specimens appeared after necking positions on the beam of the T-stub connection, shear of bolts on the column of the T-stub connection, or rupture of the T-stub connection on the beam (Figure 6b). Furthermore, after the collapse, a V-shape appeared between the T-stub and column in the beam-to-column connection location. The maximum V-shape appeared in all three groups.

\section{Conclusions}

In this research, new connection types were suggested, and their behaviors were determined using full-scale experiments. The T-shaped combinations that were created using the IPE standard profile and T-shaped elements were different from those in the literature, which used welded plates, and efficiently used residue IPE standard profiles, rather than sending them back to the consumption cycle. The main conclusions can be summarized as follows:

- The knee-range, plastic flexural resistance, maximum bending moment, bending moment capacity, and rotation of the plastic flexural resistance for the T300, T270, and T240 groups increased with an increase in $\mathrm{H}$ from $\mathrm{H}_{\min }$ to $\mathrm{H}_{\max }$.

- The thickness of the web and flange in the T-stub joints was more important than the height of the beam to height of the T-stub joint in the knee-range.

- The maximum plastic flexural resistance was obtained with an increase in the thickness of the web and flange in the T-stub joints instead of an increase in the height of the beam to height of the T-stub joint.

- The rotations of the plastic flexural resistance for the $\mathrm{H}_{\text {max }}, \mathrm{H}_{\text {min' }}$, and $\mathrm{H}_{\mathrm{av}}$ models increased by about $73.53 \%$ to $77.94 \%, 68.75 \%$ to $75 \%$, and $58.69 \%$, respectively, with an increase in the thickness of the web and flange in the T240 to T300T-stub joints.
- The maximum rotations for the T300, T270, and T240 groups decreased by about $18.53 \%$ to $36.52 \%, 25.34 \%$ to $26.02 \%$, and $36.38 \%$ to $42.79 \%$, respectively, with an increase in $\mathrm{H}_{\text {from }} \mathrm{H}_{\text {min }}$ to $\mathrm{H}_{\max }$.

- The $\Psi \mathrm{j}$ and $\Psi \mathrm{j}_{\text {max.load }_{\text {loa }}}$ values for the T300, T270, and T240 groups decreased by about $41.50 \%, 41.17 \%$ to $54.45 \%$, and $11.36 \%$ to $51.36 \%$, respectively, with an increase in $\mathrm{H}_{\text {from } \mathrm{H}_{\min }}$ to $\mathrm{H}_{\max }$

- The $\Psi \mathrm{j}$ and $\Psi \mathrm{j}_{\text {max.load }}$ values for the $\mathrm{H}_{\text {max }}, \mathrm{H}_{\text {min }}$, and $\mathrm{H}_{\text {av }}$ models decreased by about $5.13 \%$ to $77.05 \%, 65.22 \%$, and $9.11 \%$, respectively, with an increase in the thickness of the web and flange in the T240 to T300 T-stub joints.

- The energy dissipations for the T300 and T240 groups increased by about $18.56 \%$ to $20 \%$ and $48.05 \%$ to $65.96 \%$, respectively, with an increase in $\mathrm{H}$ from $\mathrm{H}_{\min }$ to $\mathrm{H}_{\max }$.

- The energy dissipations for the $\mathrm{H}_{\max }, \mathrm{H}_{\min }$, and $\mathrm{H}_{\mathrm{av}}$ models increased by about $8.33 \%$ to $36.53 \%, 21.32 \%$ to $41.17 \%$, and $37.27 \%$, respectively, with an increase in the thickness of the web and flange in the T240 to T300 T-stub joints.

\section{Acknowledgments}

The writers gratefully acknowledge the financial support given by the BAP project (2015/124) of Ataturk University and the support provided by the Gencler Metal steel company in making test specimens available. Their support in conducting the tests is most appreciated.

\section{References}

1. Sagiroglu M, Aydin AC (2015) Design and analysis of non-linear space frames with semi-rigid connections. Steel Compos Struct 18: 1405-1421.

2. Bell WG, Chesson E, Munse WH (1958) Static tests of standard riveted and bolted beam-to-column connections. University of Illinois Engineering Experiment Station, Urbana.

3. Sherbourne AN (1961) Bolted beam-to-column connections. The Structural Engineer 39: 203-210. 
Citation: Maali M, Kılıç M, Sağıroğlu M, Aydın AC (2018) Experimental Behavior of Bolted T-Stub Connections with IPE Standard Profile. J Civil Environ Eng 8: 312 doi: 10.4172/2165-784X.1000312

Page 8 of 8

4. Lewitt CW, Chesson E, Munse WH (1966) Restraint characteristics of flexible riveted and bolted beam-to-column connections. niversity of Illinois Engineering Experiment Station, Urbana.

5. Sommer WH (1969) Behavior of welded-header-plate connections. Doctoral dissertation, University of Toronto.

6. Thompson LE, McKee RJ, Visintainer DA (1970) An investigation of rotation characteristic of web shear framed connections using A-36 and A-441 steels. Department of Civil Engineering, University of Missouri-Rolla, Rolla, Missouri.

7. Surtees JO, Mann AP (1970) End plate connection in plastically designed structures. Conf. on Joints in Structures, 1(5), University of Sheffield, Sheffield, England, UK

8. Bailey JR (1970) Strength and rigidity of bolted beam-to-column connections Conference on joints in structures, Institution of Structural Engineers, University of Sheffield, UK.

9. Ostrander JR (1970) An experimental investigation of end-plate connections. Doctoral dissertation, University of Saskatchewan, at Saskatoon, Saskatchewan, Canada.

10. Packer JA, Morris LJ (1977) A limit state design method for the tension region of bolted beam-column connections. The Structural Engineer 55: 446-458.

11. Ioannides SA (1978) Flange behavior in bolted end-plate moment connections. Thesis presented to Vanderbilt University, at Nashville, Tenn., in partial fulfillment of the requirements for the degree of Doctor of Philosophy.

12. Dews RJ (1979) Experimental test results on experimental end-plate moment connections. Thesis presented to Vanderbilt University, at Nashville, Tenn., in partial fulfillment of the requirements for the degree of Master of Science.

13. Grundy P, Thomas IR, Bennetts ID (1980) Beam-to-column momen connections. J Struct Div-ASCE, 106: 313-330.

14. Bose B (1981) Moment-rotation characteristic of semi-rigid joints in stee structures. Journal of Institution of Engineers (India), Part Cl, Civil Engineering Division 62: 128-132.

15. Azizinamini A, Bradbum JH, Radziminski JB (1985) Static and cyclic behavior of semi-rigid steel beam-column connections. Deparment of Civil Engineering, University of South Carolina, Columbia.

16. Philips J, Packet JA (1986) The effect of plate thickness plate connections. J Constr Steel Res 6: 95-122

17. Moore DB, Sims PAC (1986) The influence of backing plates on the behaviour of Extended end plate connections. J Constr Steel Res 6: 95-122.

18. Davison J, Kirby BP, Nethercot A (1987) Rotational stiffness characteristics of steel beam-to column connections. J Constr Steel Res 8: 17-54.

19. Zandonini R, Zanon P (1988) Experimental analysis of end plate connections Connections in Steel Structures, Behaaior, Strength and Design (Biorhovde R, Brozzetti J and Colson A (eds), Eisevier Applied Science, London. pp: 41-51.
20. Aggarwal AK (1990) Behavior of flexible end plate beamto-column joints. J Constr Steel Res 16: 111-134.

21. Aggarwal AK (1990) Behaviour of flexible beam-to-column connections. Second National Structural Engineering Conference, The Institution of Engineers, Australia 462-467.

22. Girão Coelho AM, Bijlaard FSK, Gresnigt N, Simões da Silva L (2004) Experimental assessment of the behaviour of bolted T-stub connections made up of welded plates. J Constr Steel Res 60: 269-311.

23. Swanson JA, Leon RT, Kokan DS (2002) Advanced finite element modeling of bolted T-stub connection components. J Constr Steel Res 58:1015-1031.

24. Abidelah A, Bouchaïr A, Kerdal DE (2012) Experimental and analytical behavior of bolted end-plate connections with or without stiffeners. J Constr Steel Res 76: 13-27.

25. Herrera R, Bravo M, Gómez G, Aedo G (2013) Performance of built-up T-stubs for double T moment connections. J Constr Steel Res 88: 289-295.

26. Maali M, Aydin AC, Sağıroğlu M (2015) Investigation of innovative steel runway beam in industrial building. Sadhana, 40: 2239-2251.

27. UNE-EN 10002-1 (2002) Materiales met'alicos. Ensayos de tracci'on. Parte 1 M'etodo de ensayo a temperatura ambiente, AENOR.

28. ISO B. 898-1 (2009) Mechanical properties of fasteners made of carbon stee and alloy steel-part I, bolts, screws and studs with specified property classescoarse thread and fine pitch thread. British Standards Institute.

29. Aydın AC, Kılıç M, Maali M, Sağıroğlu M (2015) Experimental Assessment of the Semi-rigid Connections Behavior with Angles and Stiffeners. J Constr Steel Res 114: 338-348.

30. Bose B, Youngson GK, Wang ZM (1996) An appraisal of the design rules in Eurocode 3 for bolted end plate joints by comparison with experimental results. P I Civil Eng-Str B 116: 221-234.

31. Bose B, Sarkar S, Bahrami M (1991) Finite element analysis of unstiffened extended end plate connections. Struct Eng Rev 3: 211-224.

32. Schleich JB, Chantrain P, Chabrolin B, Galea Y, Bureau A, et al. (1998) Promotion of plastic design for steel and composite cross sections: New required conditions in Eurocodes 3 and 4, practical tools for designers. European commission.

33. Gil B, Cabrero JM, Gorni R, Bayo E (2003) An assessment of the rotation capacity required by structural hollow sections for plastic analysis. In: Jaurrieta MA, Alonso A, Chica JA, (eds). Tubular structures X. Lisse (Holland), A.A. Balkema Publishers pp: 277-292.

34. European Committee for Standardization (CEN) (2005) Design of stee structures. Part 1.8: Design of joints, Stage 49 draft, Brussels, Wisconsin, USA 